\title{
Case Study: Six Sigma Project for Reducing Manual Handling of Materials in Real Manufacturing Company
}

\author{
Atanas Kochov*, Aleksandar Argilovski
}

\begin{abstract}
This paper presents a case study that is focusing on the improvement of the process of materials handling in real manufacturing company. Before the implementation of this project, the company was in a concerning state of incidents and learning events towards the ergonomics, health and safety of the operators who manually handled materials as part of their daily activities. It was proposed to use the Six Sigma framework in order to improve the process or design new process for performing the task that included manual handling of materials. In this study, through selecting suitable Six Sigma framework, mapping the current process, setting key performance indicators and using various design tools and techniques, process improvement is proposed; it will solve the problem, increase ergonomics and safety, but also increase the speed of the process and reduce the cost of spilled materials that were manually handled.
\end{abstract}

Keywords: ergonomics; improvement; LEAN; manufacturing; project; Six Sigma

\section{INTRODUCTION}

Six Sigma is a structured problem-solving methodology widely used in the manufacturing industry. This paper will present the minimum number of tools that are needed during the execution of the Six Sigma project and will also give a short description of the results discovered during the study.

The Continuous Improvement department of the Company $\mathrm{A}$ is a department executing all the engineering and process improvements in the company according to the demand of the other departments. This project was initiated due to the safety issues identified during the process of dosing powder materials on an elevated platform in the production area of the Company A. The team decided to use the Six Sigma as a framework to lead this project and generate solutions through systematic and statistically supported project process.

\subsection{Brief Introduction to the Six Sigma Frameworks and Their Use in this Case Study}

At the core of the definition for the traditional Six Sigma, it is stated that it is a set of tools and techniques for problem solving and therefore improvement of the process and the products. The original Six Sigma framework consists of five phases: define, measure, analyse, improve and control [1]. This framework is also known as DMAIC framework and it is usually more applicable for improvement of existing processes or products. The DMEDI framework (define, measure, explore, design and implement) is also widely used framework when there is no existing process that can be improved, or the existing process should be completely replaced by new, significantly different process [3]. Fig. 1 presents the main deliverable of the mentioned Six Sigma frameworks and points out the differences between them [5]. The example in this case study is a DMEDI project. Each step of this framework is important for the project deliverable. Usually the team uses this framework in the feasibility study or in the detailed design phase of bigger projects [4]. In this case study, the framework was used to gather all the needed information of the proposed project and decide what will be the best conceptual design that the company should use to work on further development in the future in order to solve the existing problem.

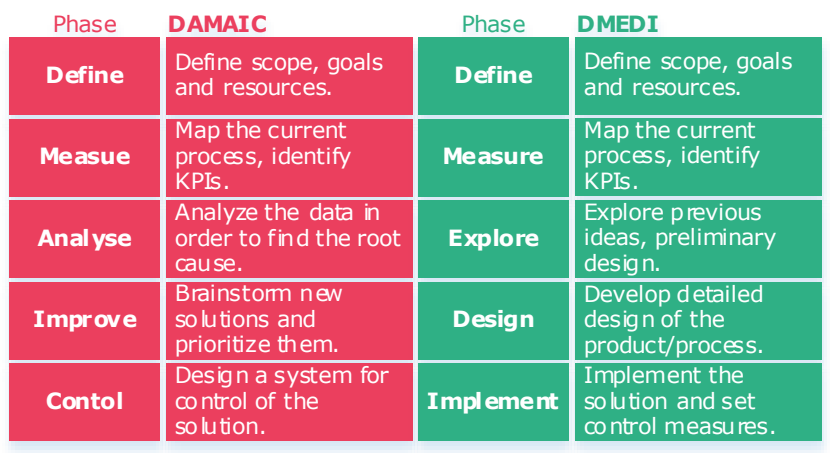

Figure 1 Six Sigma main frameworks and the deliverable for each different phase of the framework

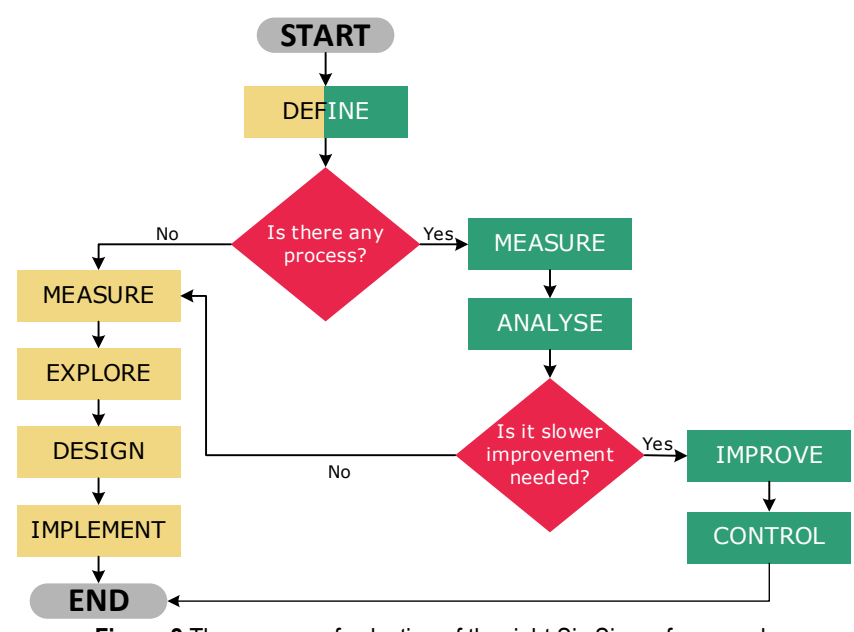

Figure 2 The process of selection of the right Six Sigma framework

The project will also establish control and monitoring plan in the last phase of the framework but will not focus on 
the project on-site implementation in order to emphasize only the Six Sigma tools and not the classical project management.

Fig. 2 presents a simple process flow diagram which can be used to decide if the project should be managed through the DMAIC or the DMEDI framework [5]. If this is not obvious at the beginning of the project, it is recommended that this decision be taken after the Define phase where the team will already gather general information on the issue, goals, the process and the resources needed.

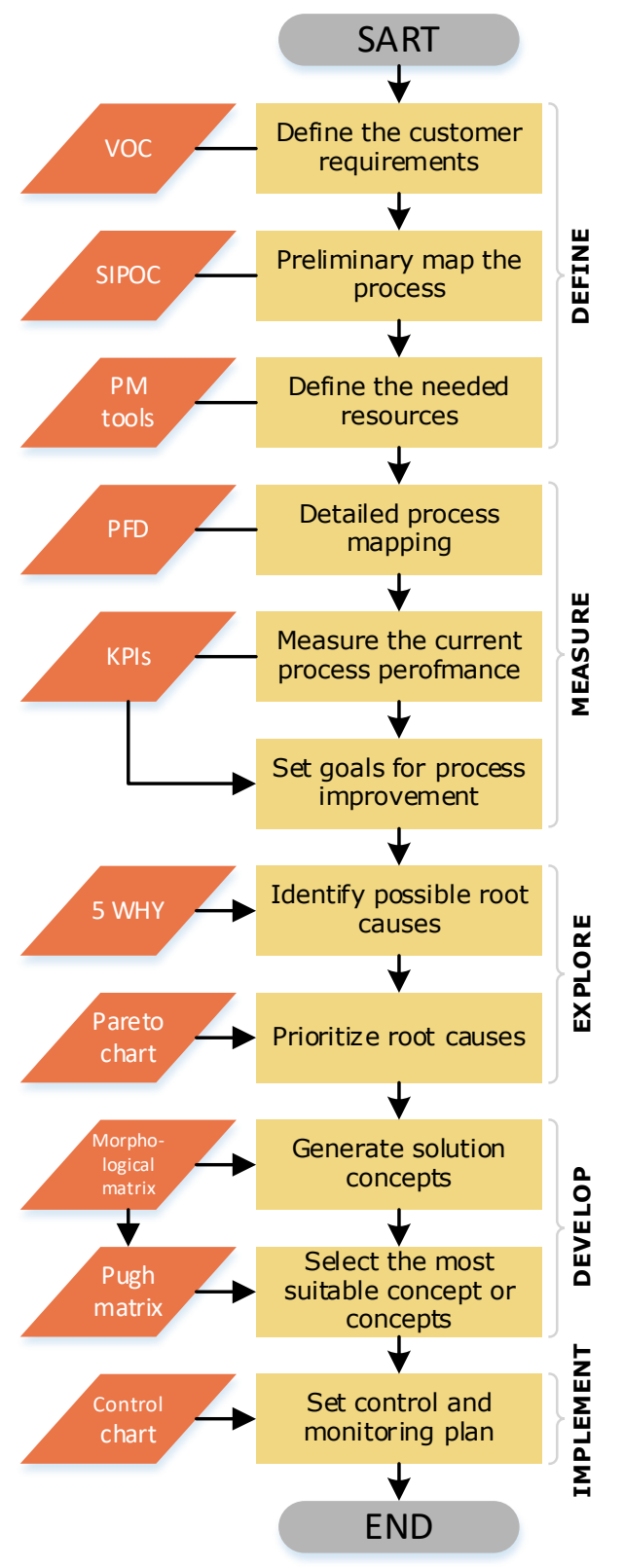

Figure 3 Six Sigma process along with tools and deliverable

\subsection{Six Sigma Tools and Deliverables}

This case study is focused on finding a practical solution for reducing the manual handling of materials in real manufacturing company. However, as stated above, it will not focus on the project management aspect of this project.
This Six Sigma project is meant to be fast and deliver as fast the statistically-based engineering solution of this issue. Therefore, optimal amount of tools was chosen for this study in order to minimize the needed time but still receive the desired deliverable at the end. Fig. 3 presents the entire Six Sigma process created for this case study along with the tools used in each of the process steps.

\section{DEFINE}

In order to successfully define the project, the least that the team should do in this phase is to collect end user requirements, preliminary map of the process, issue problem and goal statements, and define the needed resources (time, people and cost).

As stated above, at the end of this phase, the team should definitely decide if DMAIC or DMEDI framework would be followed for the project.

\subsection{Voice of the Customer}

Voice of the customer (VOC) is the easiest way to gather high-level customer/end user requirements without any detailed forms or surveys. Usually the end users (in this case the operators) are the ones that know the problem the best and solving this problem is in the field of their interest. To collect VOC, the team should simply talk to the operators, supervisors and department manager about their issues with the current process or product, write down the received comments, and then convert them in deliverable requirements together with the Six Sigma team. Fig. 4 is showing the VOC for this project.

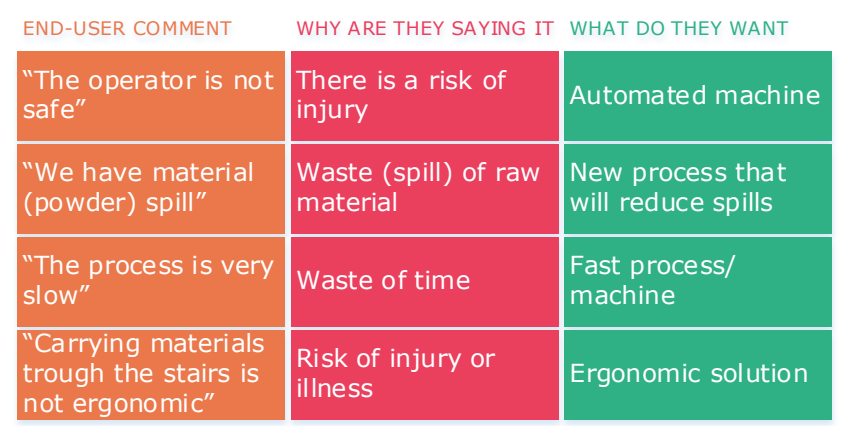

Figure 4 Voice of the customer (VOC)

This VOC table consists of three parts. The first column states the raw comments by the end users. Then, the team is filling the rest of the table after a brainstorming analysis of the comments in order to understand what the end users are saying and finally what they want to improve their experience.

\subsection{SIPOC}

The SIPOC analysis is a very useful tool for smaller improvements because with this analysis the team can sum up all preliminary information on a single sheet of paper. It is also a preliminary process mapping of the project. Fig. 5 is 
showing the SIPOC analysis for the example in this case study.

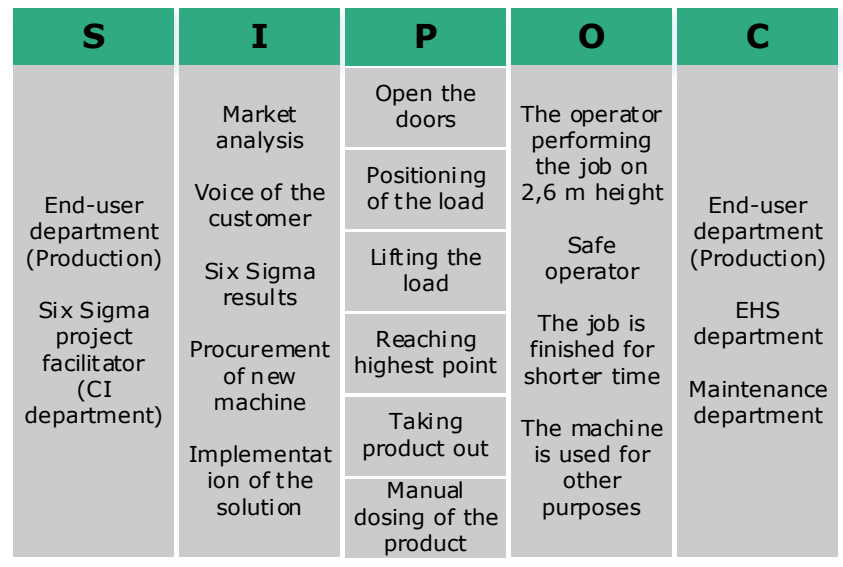

Figure 5 SIPOC

This analysis is also very flexible because it can be easily updated during the project. Through this analysis, in a very tidy and a simple way, the team can identify the following important parts of the project:

- Stakeholders (S) - everyone that is interested in the outcome of this project;

- Inputs (I) - what is needed for this project to reach its goals and deliver the needed benefits;

- Process $(\mathrm{P})$ - the steps of the current process;

- Outputs (O) - what the deliverables of the implementation of this project are (benefits can be also listed in this section);

- Customers (C) - or end users are all involved, parties that will be using the results of this project in any way.

\subsection{Resources}

This is the part of the project where project management tools set is needed to determine the needed human resources (the team), time and budget.

When it comes to resources, as a good practice it is suggested to define the Product Breakdown Structure (PBS), which will list all the final products needed at the end of this project according to the customer requirements [4]. These "products" are not only physical subjects but they can also be documents or procedures. Based on these products, the Six Sigma leader should identify the team with the needed skills to deliver these products. Cost should be defined based on relevant budgetary quotations and market analysis. When it comes to the time, many things such as internal company procedures, customer requirements, delivery terms by the vendors, availability of contractor companies etc., should be taken into consideration.

For project timeline planning, it is recommended to use the combination of Network Diagram to determinate the flow of the activities and Gantt chart to graphically show the timeline of the project and to easily have control over it.

The VOC, SIPOC and the defined resources are the inputs to the project charter, which is another Six Sigma tool that is very popular for project overview. This can be any form of a poster, which contains this information.

\section{MEASURE}

The purpose of this step is to thoroughly understand the current state of the process, collect reliable data on the process speed, quality and costs, and use that data to underlay the causes of the problems.

During this step, the current process map is in the focus. The team must understand and deeply analyze the process in order to generate key performance indicators, which at the end will show if there is any improvement, or not. A current process map, generated Key Performance Indicators (KPIs) and measured current KPIs of the current process should be considered as the main deliverables of this step.

\subsection{Current Process Mapping}

The current process for the example will be given in a simple process flow diagram (PFD) shown in Fig. 6.

The current process consists of many manual steps. First, the operator tries to find a hand pallet-truck in order to transport the materials up to the position. After that, the operator lifts materials (with the help of the pallet truck) to the highest point of a servicing platform (up to 2,6 m from the ground). While it is being lifted, the operator takes the stairs in order to reach the lifted pallet with materials. The operator reaches over the fence of the servicing platform and reaches for the raw materials placed in the bag, which is placed on the pallet. Usually the process is in a need of two operators in order to speed up the process (one operator operates with the pallet-truck and one is up on the servicing platform to manually take the material and dose it in the proper tank). When a big amount of material is not needed (less than $50 \mathrm{~kg}$ ), it usually comes in different packages (small bags) which are manually taken by the operators through the stairs up top $2.6 \mathrm{~m}$. For this case study, the Six Sigma team supervised the process several times. The process that usually occurs (with several differences from situation to situation) is presented in the process flow diagram on Fig. 6.

The process is also presented in Fig. 7 as a sketch in order to understand the process in way that is more illustrative. The sketch in Fig. 7 shows the position of the pallet and the elevated servicing platform where the bag with material is lifted.

\subsection{Key performance indicators}

Fig. 8 presents the Tree of Requirements for this project which will help the team to determine the measurable KPIs.

In order to generate the key performance indicators (KPIs), the team must have in mind the results of the VOC analysis before the Define phase. The end user requirements are the ones that should be converted into measurable indicators so that the team can track their improvement. If the generated requirements are not easily measurable, the Tree of Requirements can be used so that the requirements are converted into easily measurable indicators. 


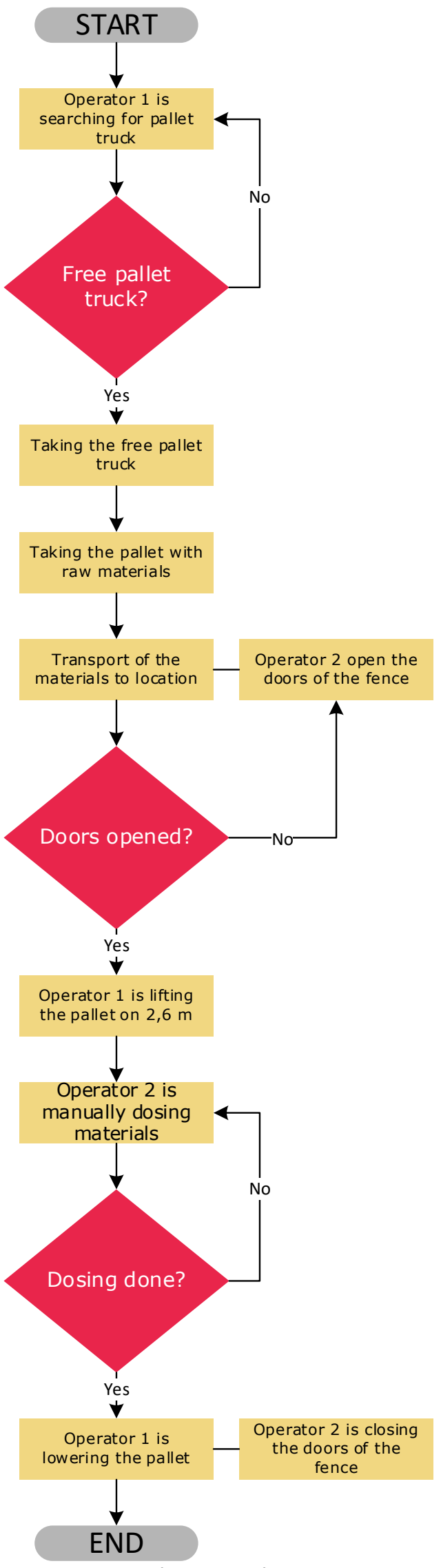

Figure 6 Process flow diagram of the current process
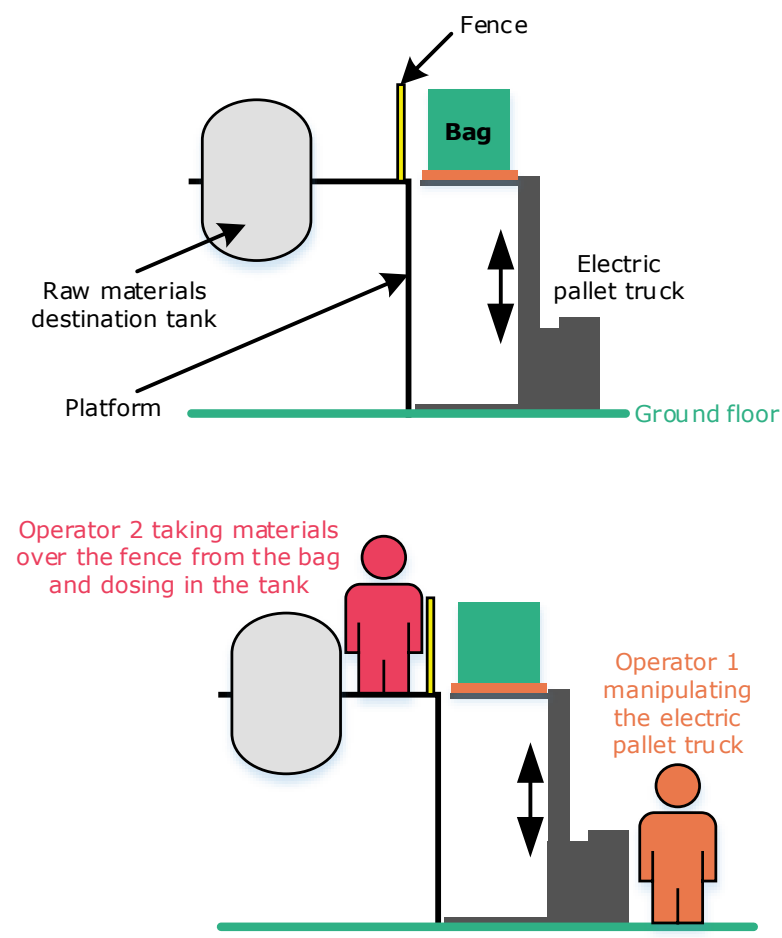

Figure 7 Sketch of the current process

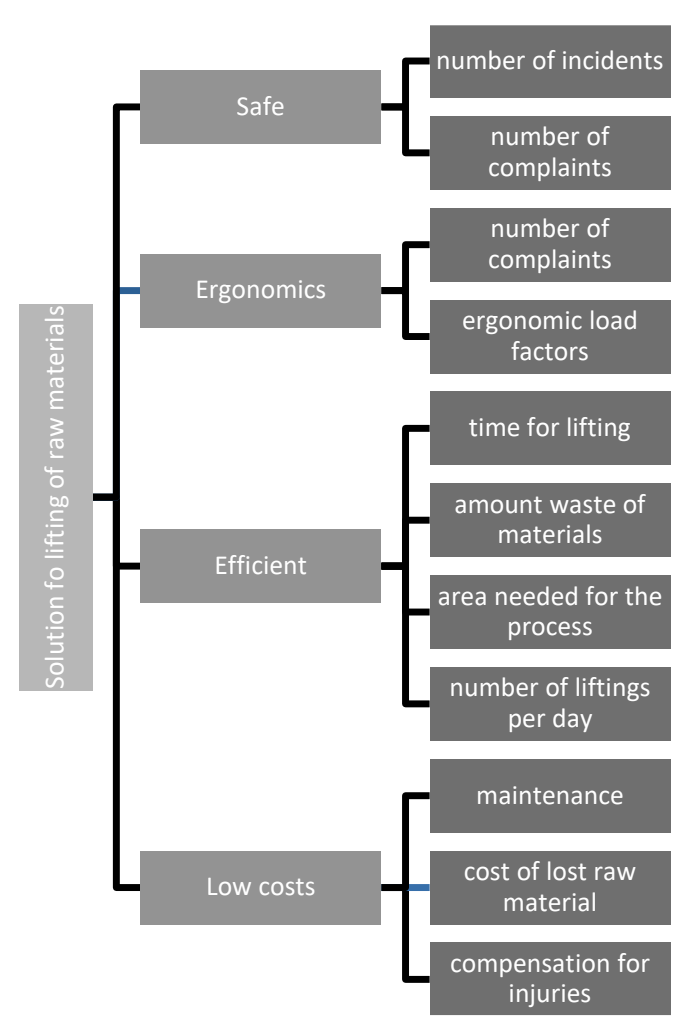

Figure 8 Tree of requirements

To explain this tool, the team highlights the requirement "waste of time/fast machine is needed". It can be already noticed that it is incredibly hard to measure this requirement and quantize it. During the Tree of requirements analysis, the team should decompose the rough end user requirement into something that can be measured with a number. For example, 
waste of time can be converted to "minutes needed for lifting the load on the servicing platform". It is known that these minutes should be as few as possible, so with measuring this indicator before and after the implementation of the solution, the team can clearly see if there was an improvement and therefore if the end user requirement is fulfilled.

If the team decides that the example above can still be decomposed in an indicator that is even easier to measure, then the requirements can be decomposed as much as they can.

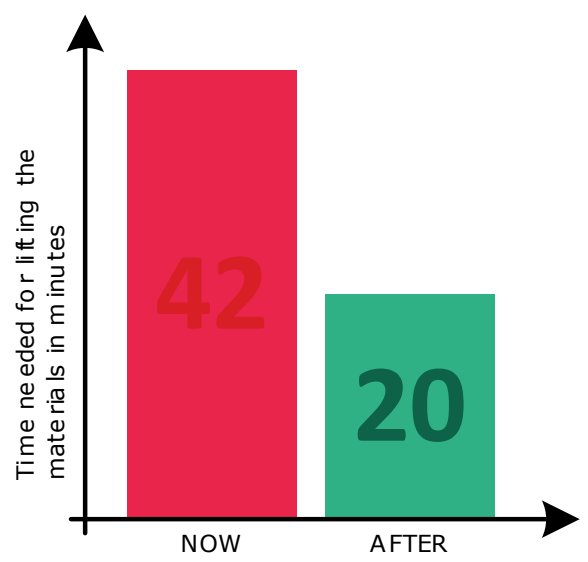

Figure 9 Time needed for lifting the materials

Figs. 9, 10 and 11 present few of the KPIs in diagrams with their current measured value. It is highly recommended that goal values be set in this phase for each indicator so that the team have initial directions "how much" to improve. The end user should set these values so that they are satisfied at the end of the project; if this is not an option, then the team should definitely set their objectives in this way.

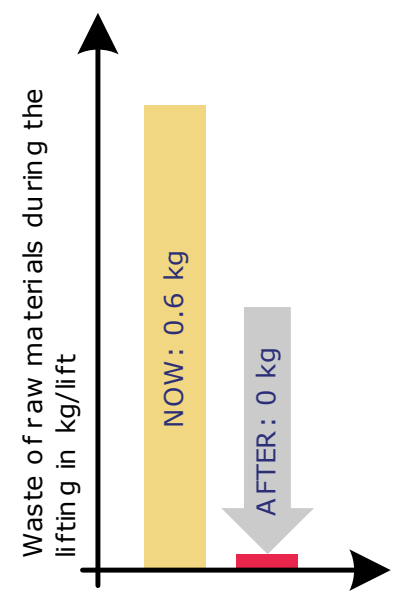

Figure 10 Waste (spill) of raw materials during the lifting

One more indicator that is not given with a diagram, but is a very important one, is that the Company $\mathrm{A}$, in the last 365 days, faced 18 incidents (injuries or illnesses of operators, spills of materials and other more serious events) and 42 complaints by the operators for the ergonomics of the lifting process. After this project, the team is expecting to reduce these numbers to 0 .

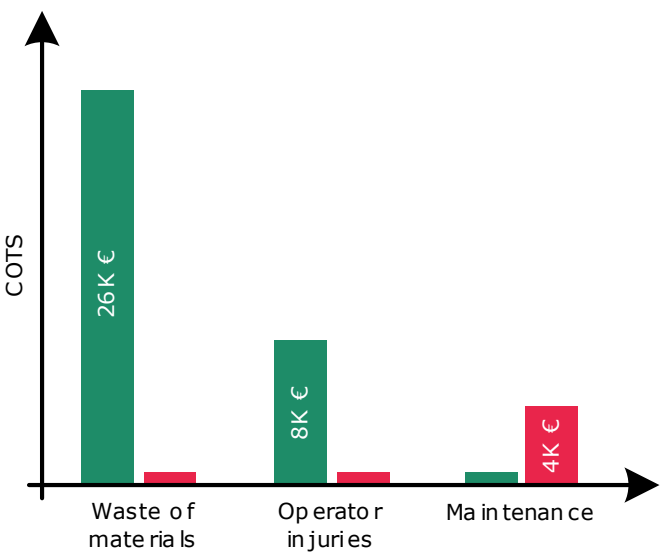

Figure 11 Costs due to spills, injuries and maintenance

\section{EXPLORE}

This is a step of the Six Sigma project that can usually be extremely short and straight-forward or it could be a deep analysis of the root causes of the problem. The main deliverable of this project is to define the root cause (or causes) of the issue and focus on solving it in the Design phase of the project. Sometimes the root cause is very obvious, but it is still recommended to use at least two tools to confirm this root cause. Pareto Chart, Fishbone diagram, 5 WHYs, 4CP analysis and many other tools can be used in this phase. For all of them, the entire team is always needed because the tools are usually based on brainstorming of possible issues.

\subsection{Why}

5 Why is interrogative and brainstorming based tool that helps the Six Sigma team to find the root cause of the problem by asking the team at least five questions that will lead to as many reasons for the issue as they can. The 5 Why analysis is given in Fig. 12.

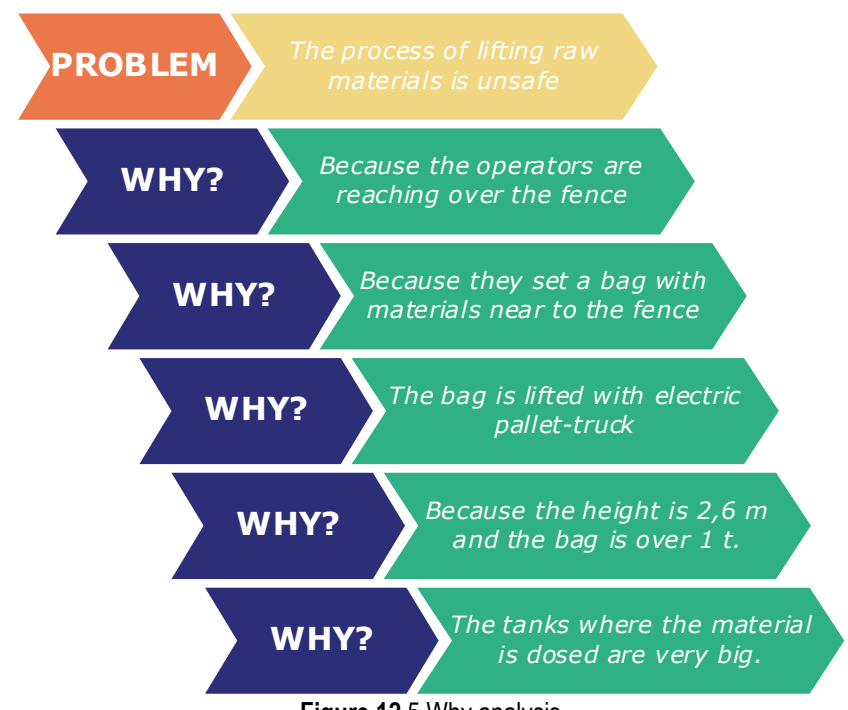

Figure 125 Why analysis

Since there is more than one reason for this issue, the 5 Why analysis for this case study will be shown only for one 
of the main problems which is "The process of lifting raw materials is unsafe". After the problem is stated, the team is asked "Why is the process of lifting raw materials unsafe?" The team should give the answer on this question based on the gathered data during the Define and Measure phases. As an answer for this question, the team suggested "The process is unsafe because the operators are reaching over the fence (to reach for the raw materials lifted on height of $2.6 \mathrm{~m}$ above the ground with a help of an electric pallet-truck)". This clearly is not the root cause of the problem, so the team is continuing with the analysis and they are asking the second "Why" based on the answer of the previous question: "Why are the operators reaching over the fence?" The process continues with another answer and question until the root cause is identified according to the team.

Sometimes there can be more root causes for one problem and that is why Pareto chart is used in order to prioritize which of these root causes are causing most of the problems in the process.

\subsection{Pareto Chart}

The Pareto chart is a very powerful tool for showing the relative importance of the occurred problems (or the root causes for these problems). The information that is input in this diagram can be collected in various ways. For this case study, the information was taken from the previously used tools in the previous phases - VOC and KPIs. In order to construct the diagram, measuring must take place. Here all indicators must be measured in same amount of time (for example in one year) and for the Pareto chart, the team is measuring the frequency of occurring of these events (not like KPIs where the team mostly measured physical units).

Table 1 Data needed for the construction of the Pareto chart

\begin{tabular}{|l|c|c|c|}
\hline \multicolumn{1}{|c|}{ Issues } & Occurrences & Cumulative & $\%$ \\
\hline Safety complaints & 42 & 42 & 43 \\
\hline Ergonomics complaints & 24 & 66 & 68 \\
\hline Load lifting operations & 15 & 81 & 84 \\
\hline No free pallet truck to do the job & 7 & 88 & 91 \\
\hline Materials spills & 6 & 94 & 97 \\
\hline Injuries due to lifting operations & 3 & 97 & 100 \\
\hline \multicolumn{2}{|r|}{ Total } & 97 &
\end{tabular}

The interpretation of this diagram is very simple. The dots of the red line (cumulative frequency) that are under the $80 \%$ cut-offline are connected to the issues that should be treated with more attention than the others because theoretically they the cause of $80 \%$ of the problems. The Pareto rule also says that if the team eliminates these highlighted issues, which are $80 \%$ of all issues, a successful improvement of the process or the product was made.

The chart highlights the issues that cause $80 \%$ of the problems (Fig. 13, dark turquoise). The other issues (Fig. 13, light turquoise) are the cause of only $20 \%$ of the problems. They are also important because they are also identified issues but the team cannot focus on so many issues and find one solution for them all. That is why it is always important to prioritize the issues. After this Pareto analysis, the team will focus on finding a solution that will be reducing the safety and ergonomics complaints during the lifting process.

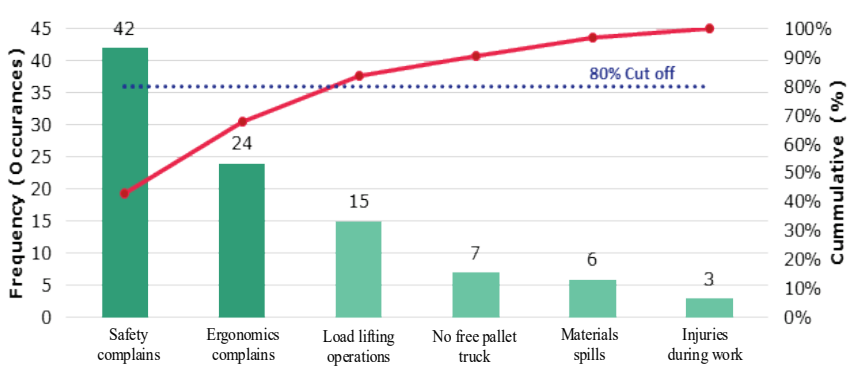

Figure 13 Pareto chart

\section{DESIGN}

As mentioned before, this Six Sigma project will not define the detailed design of the solution, nor will it generate any technical drawings for manufacturing of it but will definitely confirm the design specifications of the solution so that the solution meets the end user's requirements, improve the measured KPIs of the current process, and remove the previously identified issues with the root cause analysis.

\subsection{Morphological Matrix}

For this case study, Morphological Matrix will be used as a tool for generating new concepts. This matrix is constructed of two columns. The first column is for the needed functions of the new product/process. Next to them, in the second column, for each function the team brainstorms solutions how these functions can be executed. With combination of the different solutions (one for each function), many different concepts can be generated and after proper evaluation of the concepts according to the end users' needs, the best concept (or concepts) can be selected for further development.

\subsection{Selection of the Best Concepts}

For evaluation of the selected concepts as well as selection of the best concept, Pugh matrix will be used in this case study. The selected concepts for evaluation (according to the Morphological matrix on Fig. 14) are:

- Concept 1 (C1): 1.3, 2.1, 3.2, 4.2

- $\quad$ Concept 2 (C2): 1.2, 2.4, 3.2, 4.4

- $\quad$ Concept 3 (C3): 1.5, 2.2, 3.1, 4.1

Table 2 Pugh matrix

\begin{tabular}{|l|c|c|c|}
\hline \multicolumn{1}{|c|}{ Criteria } & C1 & C2 & C3 \\
\hline Positioning to be easy and flexible & 5 & 3 & 5 \\
\hline The current habits of the operators to be considered & 5 & 1 & 3 \\
\hline Easy for maintenance & 4 & 2 & 2 \\
\hline Can be manipulated from both close and far & 5 & 5 & 0 \\
\hline \multicolumn{1}{|r|}{ Total } & 19 & 11 & 10 \\
\hline
\end{tabular}

In the Pugh matrix, the randomly selected concepts were scored from 1 to 5 according to how much they fulfil the needed criteria (based on the end user requirements). According to the matrix, Concept 1 is the most suitable concept for the end user. This matrix can also include weighting factor. This factor will prioritize one criterion 
above the other and give them higher importance in the matrix. In this example, all the criteria have the same importance.

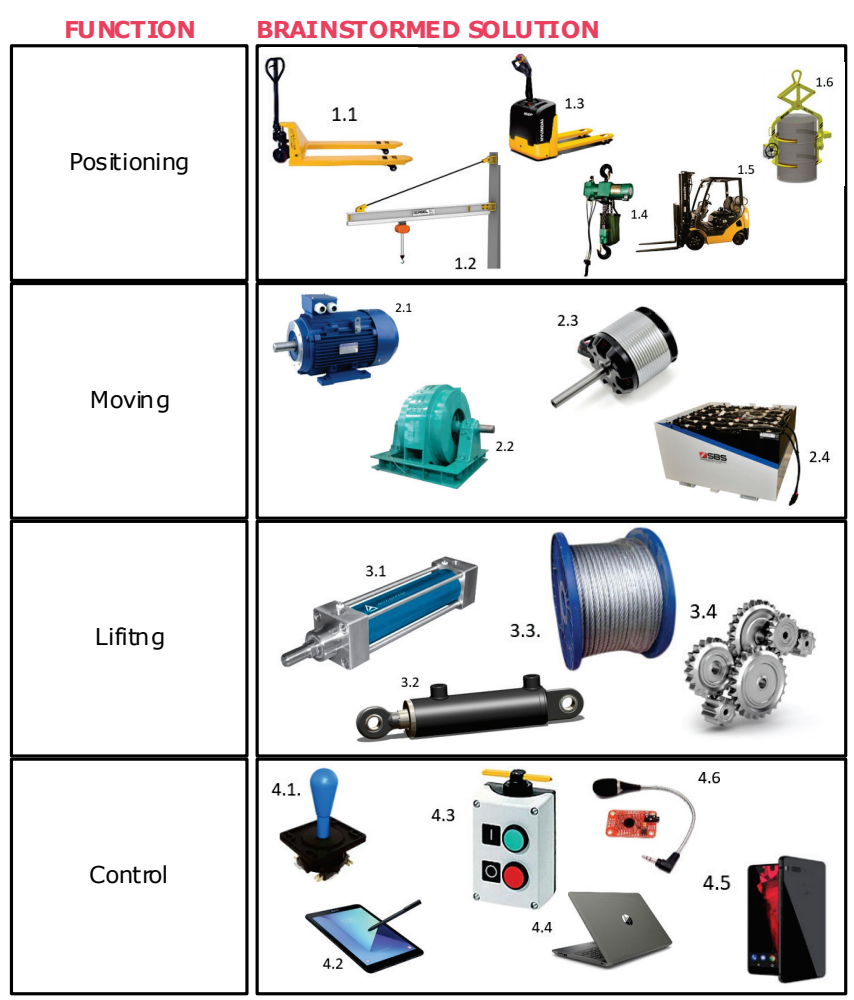

Figure 14 Morphological matrix

In order to confirm that the selection of this concept is the right one, Six Sigma offers one more tool called Force Field analysis shown in Fig. 15 [3].

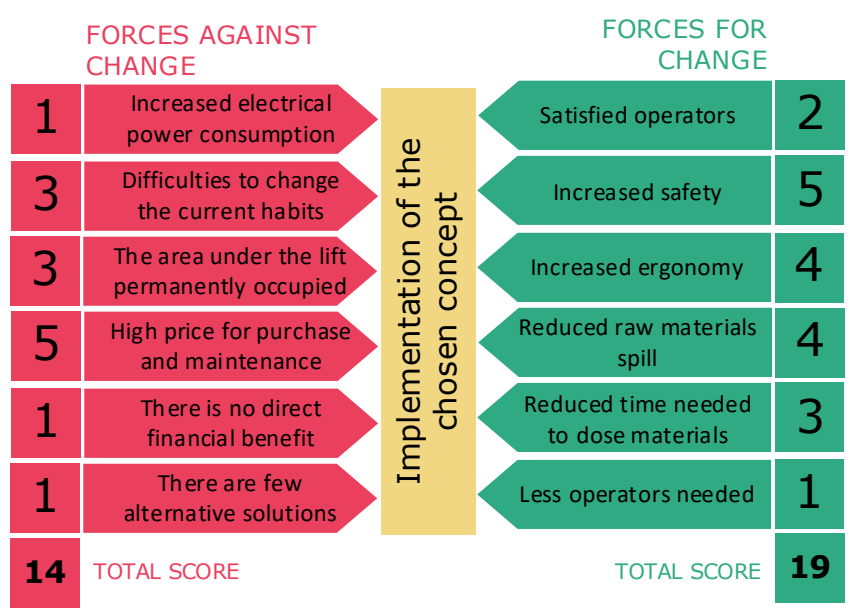

Figure 15 Force-Field analysis

\section{IMPLEMENT}

Since this project involves implementation of entirely new machine in the production area, this should undergo a heavy project management process and that is why this will not be covered in this study. The contracts with external vendors, method statements for the activities on site and other project management tools such as risk assessments for the installation, commissioning of the equipment etc., will not be a subject of this study but it is very important to say that if the project charter of the Six Sigma project in the Define phase is such that the customer is expecting these activities to occur at the end of the project, then the Six Sigma team should definitely execute the entire installation of the equipment and fulfill the agreed scope of work.

In the light of Six Sigma and the tools that it offers for this phase, few deliverables are expected for this project in the last phase: define how this solution will be sustained and set up control chart. Failure mode matrix (or FMEA) can also be executed in order to prevent any of the identified risks to become issues over the time [2].

\subsection{Sustainability and Solution Control}

For solution control and sustainability over the time, the Six Sigma suggests several options such as:

- Training for the employees - all operators that will be directly involved in the process, including their supervisors and maintenance technicians, should get detailed training about the new process and eventually the new machine that will be installed. The training should focus on ergonomics, safety and optimization of their time;

- Occasional measuring of the KPIs - plan for measuring of the established KPIs in the Measure phase must be created in order to see if the solution lost the benefits of the improvement (Control chart is a recommended tool);

- $\quad 5 \mathrm{~S}$ - setting visible labels and keeping the area tidy will help the operators to optimize the process;

- Standardized Work Instruction (or Operational procedure) - standardized procedure for work for each operator will enhance the quality of the process.

\subsection{Control Chart}

The control chart is a statistical tool that can assure the quality of the newly introduced process or product [3]. The control chart is constructed of one reference line that represents the ideal process and two margins (upper and lower margin). The fourth line is the actual process and this line is constructed of the measured values through the time for the assigned KPI. This control chart should be made for all critical KPIs identified previously in the Measure phase to assure that the solution is still an improvement compared to the old process. All the results of the measurements should be between the lower and the upper margins (of course, as close as possible to the ideal line). If any of the samples is out of the margins, that is an initial indicator that the there is a malfunction in the newly introduced process. If seven samples in a row are out of the margins, it means that there is already an issue and the improvement is degraded (improvement no longer exists).

For the case study, the team selected one of the indicators in order to create the control chart. The selected indicator is "Number of registered complaints for ergonomics in one month". This indicator at the beginning of the project (in the 
Measure phase) was 48 complaints per year, which means 4 complaints per month. In order to construct this diagram with this indicator, it must be measured every month. The upper margin for the control chart is set at three complaints per month (which is one less than the situation before the implementation of the lifting solution). The lower margin is 0 . Fig. 16 presents what the diagram looks like if the process of measuring is applied in six months after the implementation.

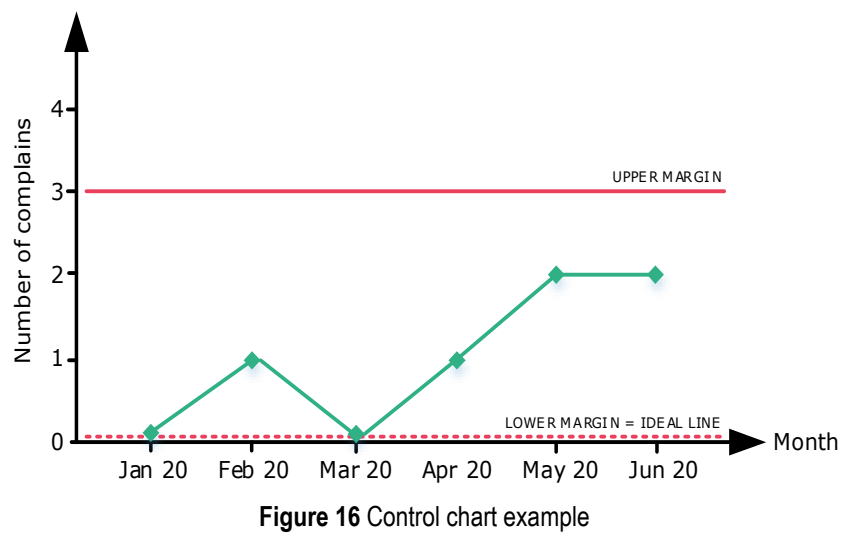

\section{CONCLUSION}

The DMEDI framework of Six Sigma is a very detailed and creative approach to finding solutions for the issues. Through this Six Sigma framework, the team managed to gather valuable information and set up initial control measures for the selected conceptual design in order to solve the identified problem that makes the work quite hard and unsafe for the operators of the Company A.

The number of Six Sigma tools was kept to the minimum of tools that are suffiecient to deliver the main and most important deliverable of this project and in the meantime satisfy the end user of this project. Such were Voice of the Customer (VOC), SIPOC, Process Flow Diagram (PFD). Tree of Requirements. Key Performance Indicators (KPI), 5 Whys, Pareto Chart, Morphological Matrix, Pugh Matrix, Force Field analysis and Control chart.

The combination of these tools made sure that Company A would receive a solution that would solve their ergonomics, safety, spills and time issues of the process of manual dosing of raw powder materials. This promotes a contemporary LEAN culture in the company. The reduction of the costs, reduction of the time needed to produce the final product and the enchantment of the quality also enhance the competitiveness of the company on the market. This shows that even smaller improvements can lead to significant changes in the companies. Besides this, the Six Sigma approach also helps in building entirely new culture in the companies, which promotes systematic approach to the problems and leads to very fast process of problem solving and end user satisfaction.

\section{Notice}

The paper was presented at MOTSP 2020 - International Conference Management of Technology - Step to Sustainable Production, which took place from $30^{\text {th }}$ September $-2^{\text {nd }}$ October 2020 in Bol, island Brač (Croatia). The paper is not and will not be published anywhere else.

\section{REFERENCES}

[1] KIT. (2015). Industrial Engineering and Management University of the State of Baden-Wurttemberg and Research Center of the Helmholtz Association. Available from: https://www.wiwi.kit.edu/downloads/2015ss_mhb_wiing_BS c_lang_en.pdf

[2] Toutenburg, H. \& Knöfel, P. (2009). Six Sigma - Methoden und Statistik für die Praxis. Springer, Berlin, p. 349.

[3] Meran, R., John, A., Roenpage, O., Staudter, C., \& Schmitz, A. (2013). Six Sigma+Lean Toolset: mindset for successful implementation of improvement projects. Second edition. Lunau, S., editor. Vol. Management for professionals. Berlin: Springer. Available from: http://ezproxy.derby.ac.uk/login?url $=$ https://www.vlebooks.com/vleweb/product/openreader?id= DerbyUni\&isbn $=9783642358821 \&$ uid $=\wedge{ }^{\wedge P M B O K}{ }^{\circledR}$ Guide Sixth Edition. (2017). A guide to Project Management Body of Knowledge, Project Management Institute.

[4] www.isixsigma.com - To use DMAIC or to use DMEDI? That is the question! - blog by Steven H. Jon

[5] Singh, S. K., Sharma, K., Kumar, D., \& Gupta, T. (2014). Role \& Importance of Lean Manufacturing in Manufacturing Industry. The International Journal of Engineering and Science (IJES), 1-14.

\section{Authors' contacts:}

Atanas Kochov, $\mathrm{PhD}$

(Corresponding author)

Faculty of Mechanical Engineering - Skopje

Karposh II bb, 1000 Skopje, Republic of North Macedonia

+389(0)71-299-299,

atanas.kochov@mf.edu.mk

Aleksandar Argilovski, BSc

Faculty of Mechanical Engineering - Skopje

Karposh II bb, 1000 Skopje, Republic of North Macedonia

+389(0)71-254-429,

argilovski@hotmail.com 